\title{
The History, Implications, and Development of the Baccalaureate Transition Resource Manual
}

\author{
Angela Macci Bires, CNMT, RT(N) ${ }^{1}$, David Gilmore, CNMT, RT(R)(N), FSNMTS ${ }^{2}$, and \\ Norman E. Bolus, MSPH, MPH, CNMT, FSNMTS ${ }^{3}$ \\ ${ }^{I}$ Nuclear Medicine Technology Program, Robert Morris University, Moon Township, Pennsylvania; ${ }^{2}$ Nuclear Medicine Technology,
Regis College, Weston, Massachusetts; and ${ }^{3}$ Nuclear Medicine Technology Program, Clinical and Diagnostic Sciences Department,
UAB School of Health Professions, Birmingham, Alabama
}

Life is full of transitions, changes, and adaptations. In this article, we will describe the developmental process and transition steps of a baccalaureate degree program in nuclear medicine technology (NMT). We will introduce a living document that was created by the leadership of the Society of Nuclear Medicine and Molecular Imaging Technologist Section (SNMMI-TS). This article suggests that the SNMMI-TS Baccalaureate Transition Resource Manual should be considered in programmatic degree criteria related to practitioner preparedness. We believe other institutions may benefit from this experience in the development of their own baccalaureate program. Our experiences may allow other institutions to have insights that will facilitate their own process for new program development. The resource manual delivers an innovative curriculum emphasizing interdisciplinary collaboration on degree content among science courses, general education courses, and additional NMT didactic completion courses. The Joint Review Committee on Educational Programs in Nuclear Medicine Technology did incorporate many of the recommendations from the Curriculum Guide for Educational Programs in Nuclear Medicine Technology, fourth edition, from the SNMMI-TS. The resource manual in conjunction with data on the transitioning of the first 3 pilot schools is the first step the SNMMI-TS has made in helping schools transition to the baccalaureate level. The manual is intended to be a living document and will be changed as additional programs make the transition and new models are created.

Key Words: resource manual; baccalaureate level; transition models; gap analysis survey

J Nucl Med Technol 2012; 40:265-270

DOI: 10.2967/jnmt.112.106773

Received Mar. 28, 2012; revision accepted May 9, 2012.

For correspondence or reprints contact either of the following:

David Gilmore, Nuclear Medicine Technology, Regis College, 235 Wellesley

St., SJH 212, Weston, MA 02493.

E-mail: david.gilmore@regiscollege.edu

Norman E. Bolus, Nuclear Medicine Technology Program, Clinical and Diagnostic Sciences Department, UAB School of Health Professions, Room

446, 1705 University Blvd., Birmingham, AL 35294-1212.

E-mail: bolusn@uab.edu

Guest Editor: Tony Knight, University of lowa Hospitals and Clinics

Published online Oct. 11, 2012.

COPYRIGHT @ 2012 by the Society of Nuclear Medicine and Molecular Imaging, Inc.

$\mathbf{G}_{\mathbf{r}}$ rowth and change in the professional field of nuclear medicine indicate a strong need for allied health professionals, particularly nuclear medicine technologists, to be educated in a 4-y program that emphasizes digital technology and new imaging modalities. The concept of health care as a team-focused process that is emphasized in degree programs seems to fit well with the development of a baccalaureate degree in nuclear medicine technology (NMT). There is a trend toward elevating the requirements for health professionals because of the complexity of technology in health care systems. History shows a trend toward interdisciplinary approaches in educational degrees. The scope of practice within our professional arena is expanding as evidenced by the recently published Nuclear Medicine Technologist Scope of Practice (1). Broadening and defining the role of an NMT are the underlying initiatives toward transitioning to a baccalaureate degree and toward establishing NMT as a specialty that has credibility. Additionally, a 2005 position paper of the Society of Nuclear Medicine and Molecular Imaging Technologist Section (SNMMI-TS) proposed that a baccalaureate degree be required by 2015 (2). What was once known as nuclear medicine technology, a somewhat singular modality, has become the profession of multimodalities and emerging technologies known as molecular imaging, with an emphasis on hybrid imaging.

\section{BACKGROUND}

The proposal that the baccalaureate degree become the standard for entry-level technologists by 2015 was first made at the annual meeting of the Society of Nuclear Medicine and Molecular Imaging (SNMMI) in June 2005. In November 2005, an educational summit was held in Reston, Virginia, to discuss the proposal and initiate a strategy to implement it. This summit resulted in the formation of an Entry-Level Task Force with 4 subcommittees: curriculum development, programmatic transition, external stakeholders, and campaign outreach.

At this summit, early reports were presented from an extensive survey by the Centers for Workforce Studies of the University of Albany conducted as part of a series of studies. 
These studies had been commissioned by the SNMMI to analyze the NMT workforce and support the forward movement of professional development and competencies. The reports substantiated a need for increasing educational content and curriculum standardization for NMT programs. Another finding of the studies indicated that "... not having a consistent educational background undercuts the reputation of the profession," (2) particularly because of a lack of standardization in curricula across programs.

The first important step in the transition process occurred at the SNMMI mid-winter meeting in February 2006 in Tempe, Arizona. At that meeting, the SNMMI-TS leadership received and approved a core-curriculum document for educational programs in NMT.

For 1 y before the Arizona meeting, the Entry-Level Task Force had drafted a core curriculum for review by program directors. The goal was to create a consistent curriculum that incorporated both professional and core curricula, because of the lack of standardization in curricula across NMT programs. The understanding was that as the core evolved, the professional curriculum would evolve as well and both could be concurrently developed. The strategy was to incorporate all required sections within a reasonable time frame.

The curriculum development subcommittee began work on the professional curriculum as committee members continued to identify several areas for growth and modification within the core curriculum. The members of the programmatic transition subcommittee were tasked with collecting and identifying barriers, roadblocks, and obstacles for existing NMT programs during the baccalaureate-level transitioning process. From this information, the committee began creating possible models for this transitioning initiative.

A strategy for a positive public relations goal was to have open communication and dialogue. The objective for this goal was to develop a symbiotic working relationship with the SNMMI-TS community at large. In compliance with this goal, the members of the external stakeholders subcommittee continued to communicate their progress and discuss issues with various stakeholders to foster their support for the transitioning initiative. Members of the campaign outreach subcommittee fulfilled their responsibilities in several public and educational forums. Presentations were delivered at the SNMMI-TS chapter meetings, and articles were written for the SNMMI-TS Uptake newsletter. A broader exposure for this initiative at the national level was achieved when the SNMMI-TS Web site was linked to concepts for papers and to discussions within the educator subgroups.

From February to May 2006, the subcommittees worked diligently to collect data and information, identify issues and key barriers, discuss possible solutions, and develop strategies to implement the transition to the baccalaureate degree.

At the annual meeting of the SNMMI in June 2006, a forum was held to discuss the entry-level initiative with educators and the general membership. SNMMI leadership announced the expansion and inclusion of our profession into the realm of molecular medicine, with emerging technologies and developments in diagnostic and therapeutic molecular medicine plotting the course for the future of nuclear medicine. The level of competence and criticalthinking skills were said to be a major factor in the education of the NMT professional. An added bonus to the outcome of discussions at the meeting was an opportunity to revise the existing scope of practice and other essential documents that would identify the tasks and responsibilities of the NMT. Again, another initiative to strengthen the professional development of the NMT profession was born. This document was written and submitted in 2011 and approved in 2012 (2).

The outcome of these discussions, information collection, and data collection resulted in a request that was made and approved by the SNMMI-TS leadership to fund an educational summit in the fall of 2006 to specifically address the programmatic transition with educators. This summit, which was held in Pittsburgh, Pennsylvania, on November 4, 2006, has come to be known as the Pittsburgh Summit. The purpose of the Pittsburgh Summit was to address the issues of programmatic transition and not to debate issues regarding the entry-level requirements for a baccalaureate degree. The rationale was that new models need to be developed to resolve any issues so as to incorporate all types of programs. The SNMMI-TS leadership felt that the transition to a baccalaureate level is necessary to advance the profession and to enable the advanced-practice path. (The advanced-practice career level, which has been christened the Nuclear Medicine Advanced Associate, was subsequently developed. The first graduating class was in June 2011.)

The Pittsburgh Summit was the impetus for our current transitioning of curricula and programs. One highlight of this event was a portrayal of the evolution of the profession and the programmatic transition. The attendees were provided with some background, as well as the degree of progress in achieving the objectives that came out of the first summit in November 2005. A brief overview of the core curriculum and of the status of the professional curriculum was given. Additionally, representatives from the American Society of Radiologic Technologists, American Registry of Radiologic Technologists, and Nuclear Medicine Technology Certification Board discussed their perspectives on the transition. Two invited guests related their experience of the pitfalls and pearls of a transition to a baccalaureate program at their own institutions (3). One of the transitions occurred during 1999-2005 and was successful. One was still in progress at that time.

At a working session, the Pittsburgh Summit attendees were asked to identify obstacles and to recommend solutions to the obstacles. This brainstorming session was just the beginning of several ongoing dialogues on not just that day but many future occasions, including discussions of how the curriculum must evolve to meet the needs of older, more educated candidates for nuclear medicine 
technologist programs. Strong statements were explored on the elements of adult learning and how education must change to meet the demands for both new content (emerging technologies) and new potential students. Questions arose, such as how and whether the new requirements would help technologists better do what they need to do. The underlying theme was that more data were needed on certification-based qualifications.

In response to the need for data on programmatic transitioning, one attendee presented data from 2 recent workforce surveys: the NMT Survey and the NMT Educators' Survey. At the time, these surveys were available on the SNMMI-TS Web site. The attendees then divided into 3 groups to discuss programmatic transition obstacles, issues, and solutions for certificate, associate degree, and 4-y programs. Attendees were free to select their discussion groups. At the closing of the summit, each group reported its findings. All relevant documents, including the minutes of the summit and slide presentations, were posted on the SNMMI-TS Web site.

At the SNMMI mid-winter meeting in February 2007, the SNMMI-TS Executive Board passed a resolution endorsing programmatic accreditation for NMT programs. Under the stewardship of the SNMMI-TS, the Educators Committee sanctioned a subcommittee of volunteers, comprising individuals with expertise in education or instructional design/ curricula, who became known collectively as the Transition Task Force Committee. The committee recognized that the accrediting/credentialing bodies, or entities that oversee the criteria for NMT programs, are the Joint Review Commission on Educational Programs in Nuclear Medicine Technology (JRCNMT) Essentials and Guidelines for Accredited Educational Programs, the Nuclear Medicine Technology Certification Board, and the American Registry of Radiologic Technologists. The accountability of NMT programs to adhere to these bodies was the driving force in the development of the Curriculum Guide for Educational Programs in Nuclear Medicine Technology, fourth edition (3).

The Transition Task Force Committee developed models for transitioning and for supporting documentation and created a gap analysis survey. The findings of the gap analysis survey were reported to the Educators Committee at the SNMMI mid-winter meeting in January 2009. These findings were reviewed by the leadership of the SNMMI-TS. Analysis of the possible gaps in a program curriculum revealed that more modules or classes were needed to cover all the content from the fourth curriculum guide. These findings subsequently led to the creation of the SNMMI-TS Baccalaureate Transition Resource Manual. This article will illustrate and describe the significance of this manual as an important resource for NMT educational programs and educators. This manual is perhaps the best first step in the process of transitioning to a baccalaureate degree in NMT.

The rationale for the need to transition from a certificate or 2-y program to a 4-y program was based on several factors. Technology is advancing at a faster rate than ever before.
Twelve-month NMT programs can no longer sufficiently cover the material that needs to be added. There needs to be a mechanism in place that teaches students not only to move forward with the new technology but also to become lifelong learners.

PET/CT is a perfect example of how the profession was not ready for this new technology and began to scramble on how both to provide CT education to current technologists and to incorporate the didactic material into educational programs. Hybrid technology continues to expand and is now commercially available in PET/CT, SPECT/CT, breast-specific $\gamma$-imaging, PET/MRI, and positron emission mammography. Radioimmunotherapy continues to progress toward becoming a reality in managing the response of tumors to therapy.

In addition to the advances in technology, another advance is that technologists are working more independently either in outpatient clinics or various hospitals and sometimes are the only technologist on staff. The ability to problem-solve and think critically is extremely important. The days of learning how to do one procedure and then moving on to another procedure are over. Today, the ability to have a knowledge base in areas outside the traditional nuclear medicine department is essential. One example is in cardiology offices, where a greater understanding of adjunctive medicine and pharmacology pertaining to these examinations is needed. This knowledge needs to go beyond just radiopharmaceuticals.

Accreditation for programs and certification for technologists has been competency-based for a few years now, and although that is good for the profession, the ability to have interdisciplinary skills is growing and has already been demonstrated in the topics addressed above. Postsecondary education in the United States has shifted to studentcentered learning that focuses on the liberal arts and the need for interdisciplinary professions.

Many of the allied health professions have pushed for a higher degree for many of the same reasons that the NMT profession is pushing for a baccalaureate degree. The goal for the profession must be to prepare individuals for the field tomorrow, not for what is happening today.

In 2009, the SNMMI-TS leadership created an Advisory Board to seek out 3 programmatically accredited NMT schools that wished to transition from a certificate or an associate degree program to a baccalaureate degree program. This was the first time the SNMMI-TS financially assisted programs in making the transition. The SNMMI-TS secured funding from the Education and Research Foundation to be used for grants to help the 3 schools offset the cost of adjunct faculty, if additional faculty was needed, and to provide travel funds for the Advisory Board to visit the schools and administer the programs. The pilot program was highly publicized and demonstrated the partnership between the SNMMI-TS and the various institutions.

The 3 schools chosen were Florida Hospital College of Health Sciences in Orlando, Florida; Northwestern Memorial Hospital in Chicago, Illinois; and Southeast Technical 
Institute in Sioux Falls, South Dakota. The Advisory Board was made up of Kathy Hunt, Kristen Waterstram-Rich, and David Gilmore (the chair of the group). The Advisory Board was under the Transition Task Force Committee chaired by Norman Bolus.

Florida Hospital College of Health Sciences and Southeast Technical Institute had associate degree programs, and Northwestern Memorial Hospital had a certificate program. Each of the 3 schools was successful in creating different models for the transition, and each presented its storyincluding the challenges, hurdles, and successes-at the SNMMI annual meeting in 2011 in San Antonio, Texas. Florida Hospital College of Health Sciences has officially changed the degree-granting award from an associate degree to a baccalaureate degree. The other 2 schools have a mechanism in place for the students to obtain a baccalaureate degree at the end of the program with another college or university via articulation agreements.

The pilot program with these initial schools was so successful in creating 3 different models that the SNMMI-TS leadership agreed to conduct another pilot program. The difference this time was that every NMT program was given the opportunity to complete an application to be a part of the second pilot program. The 3 schools selected were Chattanooga State Community College in Chattanooga, Tennessee; Gateway Community College in Phoenix, Arizona; and Research Medical Center in Kansas City, Missouri. At the time that this article was being written, the Advisory Board was working with the schools in trying to create models that will work for them.

Although the Transition Task Force Committee has been successful in establishing the resource manual and the Advisory Board to assist programs with the transition, much more work is required. The U.S. Department of Education recognizes the baccalaureate degree only if it is awarded by the sponsor of the program. This limitation drastically affects hospital-based programs and community or technical colleges in states that do not allow the institution to grant a baccalaureate degree. Because of these factors, and considering the amount of content required for preprofessional and professional education, baccalaureate education will be the most applicable level for nuclear medicine technologists of the future.

\section{THE SECTIONS OF THE MANUAL}

The SNMMI-TS Baccalaureate Transition Resource Manual has 8 sections, described below.

\section{Introduction}

This first section explains why the resource manual was developed; the section begins as follows: "The Society of Nuclear Medicine Technologist Section. . .is committed to helping educational programs transition from either certificate or associate degree, to a bachelor degree for entry level nuclear medicine technologists. This manual was developed by the SNMTS and programs that have success- fully made the transition to a BS degree. This manual is intended to be a resource for those programs that are interested in transitioning to a bachelor degree. This manual includes resources for educators to use within their organization to help that transition" (4).

\section{Statements from Professional and Certifying Organizations, SNMMI-TS, Nuclear Medicine Technology Certification Board, and American Registry of Radiologic Technologists}

This second section gives more background on the transition process and how the various organizations have developed statements that affect the need to transition: "The Society of Nuclear Medicine Technologist Section. .., Nuclear Medicine Technology Certification Board... and the American Registry of Radiologic Technologists. . .have set standards required for the entry level nuclear medicine technologist. You will find supporting documents from these organizations in this tab." (4-7).

\section{JRCNMT Standards}

This third section gives information on the JRCNMT and contains a copy of the most recent changes to the standards: "The Joint Review Committee on Educational Programs in Nuclear Medicine Technology (JRCNMT) was founded in 1969 by collaboration between the American College of Radiologists, the American Society for Medical Technology, the American Society of Clinical Pathologists, the American Society of Nuclear Medicine and the Society of Nuclear Medicine Technologists. The goal was to establish, maintain and promote standards of quality for educational programs in nuclear medicine technology with the desired goal of providing skilled professional services to the patients that they served. Also, in 1969 the collaborating organizations adopted the Essentials and Guidelines. The purpose of this document was to identify the minimum standards of quality for accredited programs that prepare individuals to enter the profession of Nuclear Medicine Technology. These standards have been reviewed and revised along the way (specifically 1976, 1984, 1991, 1997, 2003 and 2010). In 2010 the JRCNMT changed the name of this document to Accreditation Standards for Nuclear Medicine Technologist Education which became effective in 2011. In 1970 the JRCNMT, in collaboration with the American Medical Association. . .Council of Medical Education..., began accrediting educational programs in nuclear medicine technology. Educational programs, which meet or exceed the minimum standards, are granted accreditation by the JRCNMT, thus providing public recognition of their achievement" (5).

\section{Curricula}

This fourth section explains the process by which the fourth curriculum guide from the SNMMI-TS was created: "In 2008, the Society of Nuclear Medicine Technologist Section. . formed an Educators Task Force Curriculum Subcommittee based on the proposal that by the year 2015 , education leading to the baccalaureate degree become the 
standard for entry level nuclear medicine technologists. The Educators Task Force Curriculum Subcommittee recognized that the profession of nuclear medicine technology has experienced significant advancements in technology and molecular science. As the field has advanced, the scope of practice for nuclear medicine technologists has increased. The need for critical thinking and the ability to respond to clinical, organizational, and fiscal demands facing the health care industry supports the creation of a multi-skilled technologist to perform nuclear medicine imaging studies and provide assistance with radionuclide therapy treatments. The Society of Nuclear Medicine Technologist Section Entry-Level Curriculum includes a general education core that lists required courses in math, science, and the liberal arts. These courses are intended to prepare students for entry into the professional component of the nuclear medicine technologist program. Also included is a list of optional preparatory coursework that could further enhance the educational curriculum for any nuclear medicine technology program.

"It is the belief of the Society of Nuclear Medicine Technologist Section that the general educational core curriculum will provide nuclear medicine technology students with the necessary foundation for the successful completion of the professional component of a nuclear medicine technology program."

\section{Gap Analysis}

This fifth section is a copy of the gap analysis with an explanation of how to use it to begin identifying gaps in a curriculum. Transitioning programs found this tool useful in directing them toward what was needed and what resources were available to help them align with the fourth curriculum guide. A gap analysis is a means of identifying how well programs meet an external standard. For the transition to baccalaureate level, the Transition Task Force Committee developed a survey, which is included in its entirety in this section. The external standard used for the survey is the fourth curriculum guide, developed by the SNMMI-TS in 2008. Schools use the survey by identifying which individual items apply to their own programs. The areas of the survey include prerequisites, didactic hours in the professional curriculum, and emerging technologies (both didactic and clinical hours). The gaps are the items that a school's current program does not address (8).

Following the survey and a task-force-generated list of potential gaps are the results of the survey administered in January-March 2009 (56/97 survey forms were returned), allowing schools to compare their programs with others across the nation. Finally, the actual gap analysis survey results for the programs of 3 schools are shown. One offers an associate-level degree, the second offers certificate and associate degrees, and the third offers a baccalaureate degree and a certificate. The Transition Task Force Committee is working with these 3 programs as the prototypes for transition; the gap analyses of these programs will link to their information in the transition models section.

\section{Transition Models}

The Educators Task Force Committee developed transition models to act as a guide in assisting various types of NMT programs. In this sixth section, associate programs can locate a 2-plus-2 model in which the student graduates with an associate degree and then completes the baccalaureate requirements on campus or online. The second model describes community colleges that may want to consider offering baccalaureate programs. The third model can be used by certificate programs or other programs by building a multiinstitutional consortium.

Section 7 describes barriers in the transition to a baccalaureate degree. These will depend not only on the personnel of each institution but also on state legislature and governing bodies, which may play a role as well. For example, the personnel of some state universities were vocal in their desire to keep the 4-y degrees at their institutions. More expected obstacles include the setting of new timelines and hiring of new faculty, as well as reaccreditation, marketing, and the financial impact. Programs that recently completed their transition have shared their personal experiences with these barriers. The Educators Task Force Committee hopes their narratives in this section and the next may facilitate the transitioning of other programs (3).

Section 8 describes the personal experiences of several programs in their transitioning process to a baccalaureate program. Some programs had unique circumstances to overcome whereas others experienced more general obstacles. A review of all their accounts may help guide programs in their transition. This section begins with a survey filled out by programs that had already completed the transition. Stories about the specific experiences of programs follow (3).

\section{CONCLUSION}

The resource manual in conjunction with data gathered from the first 3 pilot schools is the first step the SNMMI-TS has made in helping schools transition to the baccalaureate level. The resource manual is intended to be a living document, and changes will occur within the manual as additional programs make the transition and new models are created. Although some of the transition models do not warrant a baccalaureate degree in NMT or a related field such as medical imaging or radiologic sciences, they do address the need for a pathway for students to earn a baccalaureate degree that incorporates the credit and contact hours earned while obtaining an associate-level degree or certificate.

The resource manual, by providing the gap analysis, new curriculum models, and transition models, will assist program directors and educators in evaluating their own program if they wish to transition as recommended 
by the SNMMI-TS. Although not all programs may meet the original SNMMI-TS goal of having an entry-level baccalaureate degree as a minimum standard by 2015 , resources and contacts are now available to help programs that do want to move forward. We recommend that schools having associate degree and certificate programs review the resource manual to determine whether the material applies to them and, if not, provide suggestions to the SNMMI-TS.

Finally, because of the recommendation that all programs transition to the baccalaureate level, it has been suggested that a new white paper be developed that highlights changes in the profession and education. This paper should include the rationale for why a baccalaureate degree is recommended, the approaches that were taken to reach this recommendation, and the overall changes that have occurred in the profession, scope of practice, and education.

\section{ACKNOWLEDGMENT}

We acknowledge the Educators Task Force Committee, the Transition Task Force Committee, the Advisory Board, the Resource Manual Working Group (2009-2010), the
SNMMI-TS leadership, and Lynn Barnes. No potential conflict of interest relevant to this article was reported.

\section{REFERENCES}

1. Nuclear medicine technologist scope of practice. SNMMI Web site. Available at: http://interactive.snm.org/docs/Scope_of_Practice_NMT_6-8-2012_FINAL.pdf. Accessed September 21, 2012.

2. The Society of Nuclear Medicine Technologist Section (SNMTS) proposes baccalaureate degree become the standard for entry level nuclear medicine technologists by 2015. SNMMI Web site. Available at: http://interactive.snm.org/index. cfm?PageID=4715. Accessed September 21, 2012.

3. SNMTS baccalaureate transition resource manual. SNMMI Web site. Available at: http://interactive.snm.org/docs/communities/SNMTS\%20Resource\%20Manual\% 20-v2\%20\%281-3-11\%29.pdf. Accessed September 21, 2012.

4. Accreditation standards for nuclear medicine technologist education. JRCNMT Web site. Available at: www.jrcnmt.org/program-resources. Accessed October 5, 2012.

5. Components of preparedness. NMTCB Web site. Available at: http://www.nmtcb. org/exam/cops.php. Accessed September 21, 2012.

6. Content specifications. ARRT Web site. Available at: https://www.arrt.org/ pdfs/disciplines/content-specification/nmt-content-specification.pdf. Accessed October 4, 2012.

7. Nuclear medicine practice standards. ASRT Web site. Available at: https://www.asrt. org/docs/educators/snmtscurriculumguide4thed.pdf. Accessed October 4, 2012.

8. Bires AM, Mason DL, Gilmore D, Pietrzyk C. Gap analysis survey: an aid in transitioning to standardized curricula for nuclear medicine technology. $\mathrm{J} \mathrm{Nucl}$ Med Technol. 2012;40:178-182. 